\title{
DEFAUNATION EFFECTS OF MEDIUM-CHAIN FATTY ACIDS AND THEIR DERIVATIVES ON GOAT RUMEN PROTOZOA
}

\author{
MITSUTO MATSUMOTO, ${ }^{* \dagger}$ TAKERU KOBAYASHI, AKIO TAKENAKA, \\ AND HISAO ITABASHI
}

National Institute of Animal Industry, Tsukuba 305, Japan

(Received September 10, 1991)

\begin{abstract}
Nine castrated Japanese Saanen goats were used to investigate the effects of saturated fatty acids and their derivatives on the rumen ciliate protozoa. The goats were first fed a test diet composed of $500 \mathrm{~g}$ of basal diet and $25 \mathrm{~g}$ of one of the following: caprylic acid (C8), capric acid (C10), lauric acid (C12), myristic acid (C14), palmitic acid (C16) or stearic acid (C18). C10 proved to be the most toxic for the protozoa. Progressively less inhibition was displayed with either an increase or a decrease in the carbon chain length. Second, calcium (Ca) salts and triglycerides (TG) of C8 and C10 were applied. With the feeding of C10Ca or C10TG, the protozoa in the rumen disappeared. The toxic effects of free fatty acids were not alleviated by the derivatives. Third, protozoa other than Epidinium in a mixed-faunated goat disappeared after the feeding of hydrated coconut oil (52\% lauric acid). Capric acid and its derivatives are considered useful rumen-defaunating agents. Lauric acid and its derivatives might be used to establish Epidinium mono-faunated animals.
\end{abstract}

Nowadays, dietary fat is increasingly used as an energy source for dairy cows in order to meet the high-energy demand of milk production, especially during early lactation $(16,18)$. It has been pointed out, however, that the addition of fat to ruminant diets can cause a decrease in ruminal fiber and organic matter digestion and methanogenesis, ammonia concentration and acetate/propionate ratio (16). It is also well known that fatty acids inhibit the growth of certain strains of rumen bacteria $(6,11)$. In addition, it has been shown that unsaturated long-chain fatty acids $(2)$ and some lipids $(1,14,19)$ have antiprotozoal effects.

These facts taken together suggest that saturated fatty acids, as opposed to

\footnotetext{
* Address reprint requests to: Dr. Mitsuto Matsumoto, Tohoku National Agricultural Experiment Station, Morioka 020-01, Japan.

${ }^{\dagger}$ Present address; Tohoku National Agricultural Experiment Station, Morioka 020-01, Japan.
} 
unsaturated fatty acids, have an inhibitory effect on rumen protozoa. In conventional ruminants, digestion in the rumen is carried out by ciliate protozoa as well as bacteria. We therefore studied the effect of feeding saturated fatty acids and their derivatives on rumen protozoal populations in vivo using Japanese Saanen goats.

\section{MATERIALS AND METHODS}

Materials. The fatty acids and derivatives employed were caprylic acid (C8), capric acid (C10), lauric acid (C12), myristic acid (C14), palmitic acid (C16), stearic acid (C18), calcium salts of $\mathrm{C} 8$ and $\mathrm{C} 10$ (C8Ca and $\mathrm{C} 10 \mathrm{Ca}$ ) and triglycerides of $\mathrm{C} 8$ and $\mathrm{C} 10$ (C8TG and C10TG). The purity of all chemicals were greater than $90 \%$. $\mathrm{C} 8 \mathrm{Ca}$ and $\mathrm{C} 10 \mathrm{Ca}$ contained $45 \%$ moisture. Fatty acid compositions (wt \%) of hydrated coconut oil were as follows, C8 3, C10 3, C12 52, C14 15, C16 7.5, and C18 19.5. All of them were kindly donated by Kao Corporation (Tokyo).

Animals. Nine castrated Japanese Saanen goats weighing 20 to $25 \mathrm{~kg}$ were used. Entodinium spp., Dasytricha ruminantium, and Isotricha spp. were present in the rumen contents of all the goats. Epidinium caudatum was found in three of the goats. Polyplastron multivesiculatum and Ophryoscolex caudatus were found in the other six. When the goats were used in feeding trials of fatty acids and their derivatives, the mean concentration of protozoa just before feeding was over $1.0 \times$ $10^{5} / \mathrm{ml}$. When necessary, the goats defaunated through the feeding of fatty acids were reinoculated with a mixed-ciliate population containing Epidinium caudatum from adult goats of the stock herd at the National Institute of Animal Industry. The goats were fed a basal diet consisting of $300 \mathrm{~g}$ of Italian ryegrass hay wafer, 175 $\mathrm{g}$ of concentrate pellets and $25 \mathrm{~g}$ of molasses once daily at $09: 30$. Water and mineral blocks were always available. Each animal was kept in a room under controlled temperature conditions $\left(26^{\circ} \mathrm{C}\right)$, and kept in a cage to prevent contact with the other animals.

Examination of protozoa. Four trials were conducted. In each trial, rumen samples for microscopic examination of the protozoa were taken using stomach tubes just before feeding. Protozoal numbers were counted using a FuchsRosenthal counting chamber (9).

Trial 1 (Free fatty acid feeding trial). Twenty-five grams of C8, C10, C12, $\mathrm{C} 14, \mathrm{C} 16$ and $\mathrm{C} 18$ were added to the basal diet. A test diet composed of $500 \mathrm{~g}$ of basal diet and $25 \mathrm{~g}$ of each of the six free fatty acids was given to 3 goats for 5 days. Each treatment contained at least one goat faunated with Epidinium.

Trial 2 ( $\mathrm{C} 8 \mathrm{Ca}$ or $\mathrm{C10Ca}$ feeding trial). With the C10Ca feeding, a test diet composed of $500 \mathrm{~g}$ of basal diet and $25 \mathrm{~g}$ of $\mathrm{C} 10 \mathrm{Ca}$ (fresh matter basis) was given to 5 goats during the first 8 days, followed by the basal diet alone for 14 days. With $\mathrm{C} 8 \mathrm{Ca}$ feeding, 4 goats were given $25 \mathrm{~g}$ of $\mathrm{C} 8 \mathrm{Ca}$ on days 1 to 8 , while from day 9 to $18,50 \mathrm{~g}$ of $\mathrm{C} 8 \mathrm{Ca}$ was given.

Trial 3 (C8TG or C10TG feeding trial). A test diet composed of $500 \mathrm{~g}$ of 
basal diet and $25 \mathrm{~g}$ of C8TG or C10TG was given to the goats (3 goats for each treatment) for 12 days. The basal diet alone was then given for 10 days. Changes in the protozoal numbers were observed.

Trial 4 (hydrated coconut oil feeding trial). As over $50 \%$ of the fatty acid content of hydrated coconut oil is $\mathrm{C} 12$, this trial was carried out to clarify the defaunation effect of $\mathrm{C} 12$ on Epidinium caudatum. The reason for this was that in Trial 1, only Epidinium caudatum did not disappear after C12 feeding. Two goats were used. One of them was an Epidinium mono-faunated goat (rumen protozoal population consisting of Epidinium caudatum only), which was established with a 5-day feeding of $25 \mathrm{~g}$ of $\mathrm{C} 12$ in Trial 1 . The goat was given the test diet composed of $500 \mathrm{~g}$ of basal diet and $30 \mathrm{~g}$ of hydrated coconut oil for 10 days. The other goat (a mixed faunated goat with a rumen protozoal population consisting of Entodinium spp., Dasytricha and Epidinium) was given the test diet for 25 days.

\section{RESULTS}

Addition of free fatty acids to the diets resulted in a decrease in appetite, but fatty acid derivatives resulted in a good appetite.

Figure 1 shows the effects of free fatty acids on rumen protozoa. Ciliate protozoa disappeared from the rumen contents taken from goats fed $\mathrm{C} 10, \mathrm{C} 12$ or C14 for five successive days. However, two weeks after withdrawal of C12, Epidinium caudatum reappeared in one goat. This goat was used in Trial 4. With

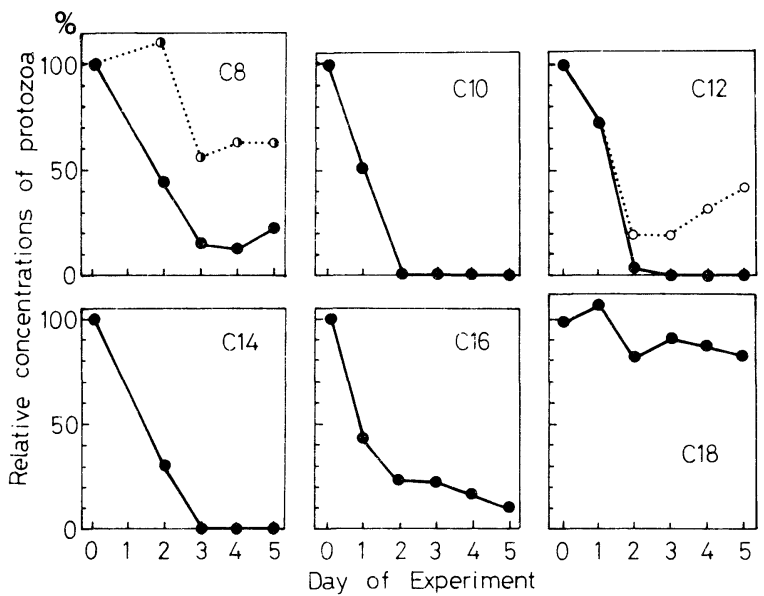

Fig. 1. Effect of saturated fatty acids on the concentration of protozoa in the rumen contents of goats.

The figures are expressed relative to a count of 100 on day 0 (just before fatty acid feeding). Each value is the mean for 3 animals. C8; caprylic acid, C10; capric acid, C12; lauric acid, C14; myristic acid, C16; palmitic acid, C18; stearic acid. total protozoa, : Epidinium caudatum in the Epidinium mono-faunated goat, Dasytricha ruminuntum. 
goats fed $\mathrm{C} 14$, mixed populations were found again in the rumen contents two weeks after the withdrawal of $\mathrm{C} 14$. The concentration of protozoa decreased with the feeding of $\mathrm{C} 8, \mathrm{C} 16$ or $\mathrm{C} 18$, but was not eliminated completely. The toxic effects of $\mathrm{C} 8$ on Entodinium spp. seem to have been stronger than those on Isotrichids (Dasytricha). These results clearly demonstrate that medium-chain fatty acids are the most inhibitory and progressively less inhibition is displayed with increase or decrease in the carbon chain length. C10 appears to be the most toxic.

Figure 2 shows the effects of $\mathrm{C} 8 \mathrm{Ca}$ and $\mathrm{C} 10 \mathrm{Ca}$ on rumen protozoa. With the feeding of $25 \mathrm{~g}$ of $\mathrm{C} 10 \mathrm{Ca}$ for 9 days, the protozoa disappeared. After the withdrawal of the $\mathrm{C} 10 \mathrm{Ca}$, protozoa did not appear again during Trial 2. A diet of

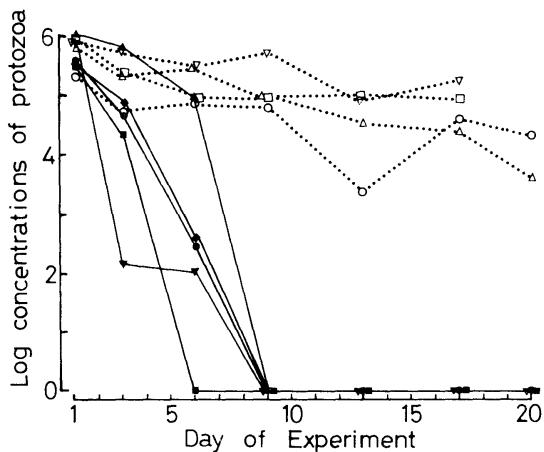

Fig. 2. Defaunation effect of calcium salts of $\mathrm{C} 8$ and $\mathrm{C} 10$ ( $\mathrm{C} 8 \mathrm{Ca}$ and $\mathrm{C} 10 \mathrm{Ca})$.

Open symbols and dotted lines show goats fed $\mathrm{C} 8 \mathrm{Ca}$ and closed symbols and solid lines show goats fed $\mathrm{C} 10 \mathrm{Ca}$. C10Ca was given on days 1 to 9 , at level of $25 \mathrm{~g}$ (fresh matter). With $\mathrm{C} 8 \mathrm{Ca}$, on days 1 to $9,25 \mathrm{~g}$ was given, and then, on days 10 to $18,50 \mathrm{~g}$ of $\mathrm{C} 8 \mathrm{Ca}$ was given. Each symbol represents the value for an individual goat. Samples of rumen contents for determining protozoal numbers were collected just before feeding.

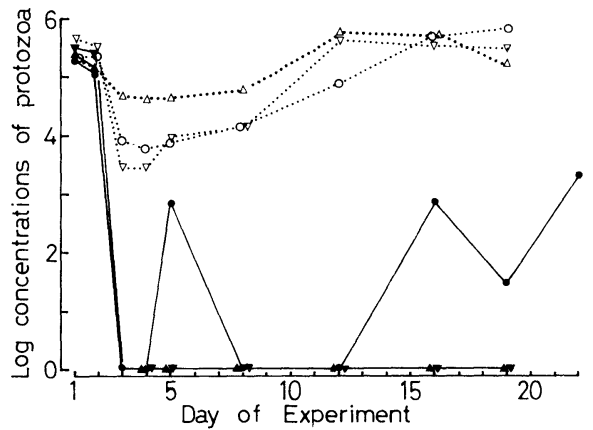

Fig. 3. Defaunation effect of C8-triglyceride (C8TG) and C10-triglyceride (C10 TG).

Twenty-five grams of each TG were given per head per day on days 1 to 12 , thereafter, TG was not supplied. Other details are the same as shown in Fig. 2. 
$25 \mathrm{~g}$ of $\mathrm{C} 8 \mathrm{Ca}$ did not make protozoa disappear, so $50 \mathrm{~g}$ of $\mathrm{C} 8 \mathrm{Ca}$ was given for 9 days. Nonetheless, the protozoa did not disappear from the rumen. This shows that the defaunation effect of $\mathrm{C} 10 \mathrm{Ca}$ is stronger than that of $\mathrm{C} 8 \mathrm{Ca}$. It also shows that the toxicity of free fatty acids is not reversed by saponification of fatty acids using Ca.

The effects of C8TG or C10TG were almost the same as those for Ca-salts of $\mathrm{C} 8$ or $\mathrm{C} 10$ as shown in Fig. 3. Rumen ciliate protozoa disappeared from two goats fed C10TG. This defaunated condition was maintained for more than one year. Protozoa in the remaining one goat fed C10TG disappeared once, but Epidinium caudatum was found again 5 days after the end of the C10TG feeding. Feeding of C8TG caused a rapid decrease in the concentration of protozoa during the first 3 days of the experiment. However, after day 5, the concentration of protozoa increased gradually, and on day 12 it was almost the same as on day 1.

The Epidinium in the Epidinium mono-faunated goat did not disappear with a 10 day-feeding of $30 \mathrm{~g}$ of hydrated coconut oil. Protozoa other than Epidinium in a mixed-faunated goat disappeared after a feeding of $30 \mathrm{~g}$ of hydrated coconut oil for 3 days, but Entodinium spp. appeared again on day 25 of the trial. This confirmed the results obtained in Trial 1.

\section{DISCUSSION}

Three major types of experimental methods for artificial defaunation are available (7). One involves the destruction of protozoal cells by chemicals such as dioctyl sodium sulphosuccinate, etc. Defaunation using free fatty acids or their derivatives as in the present experiment is a modification of chemical defaunation. Although coconut oil, linseed oil and soya oil hydrolysate have all been reported to have antiprotozoal effects (7), our results clearly show a relationship between toxicity and carbon chain length of fatty acids and indicate that $\mathrm{C} 10$ fatty acid and its derivatives have a stronger toxicity than fatty acids having shorter and longer carbon chains. As calcium salts or triglycerides of medium-chain fatty acids (C10 or C12) permit a good appetite, they seem to be useful agents for defaunation.

This report clearly illustrates the toxic effects of medium-chain fatty acids on rumen protozoa, but medium-chain fatty acids also have been shown to have a bacteriocidal or bacteriostatic activity $(3,8,15)$. Many derivatives of mediumchain fatty acids have been used as antibacterial agents $(3,8)$. Though the mechanisms of this antibacterial activity are not fully understood, some theories have been proposed $(10,12,13,20)$. Among these, adsorption of free fatty acids onto the bacterial cell surface $(12,13)$, destruction of the proton-motive force across the cell membrane (10), surface-activity effects on the cell membrane (12), fatty acidinduced cellular lysis (20), etc. have been postulated. The defaunation effects of medium-chain fatty acids might also be the result of a combination of these factors.

It has been reported that the inhibition of microbial activity caused by dietary fat can be reversed by the addition of metal cations, such as $\mathrm{Ca}$ and $\mathrm{Mg}$ (4). This 
effect can be explained in terms of forming insoluble soaps of fatty acids and cations. This is one of the reasons why Ca-salts of fat are included in rations for dairy cattle. The present results suggest, however, that the toxicity of C10Ca to protozoa seems to be similar to that of C10TG. This means that the antimicrobial effects of dietary fat are not reversed by the addition of metal cations if the fat contains a large amount of medium-chain fatty acids. It will be necessary to evaluate the biological significance of each fatty acid, especiaily medium-chain fatty acids, as supplementing cattle diets with medium-chain fatty acids has been examined recently $(5,17)$.

We are grateful to Mr. T. Iwasaki and Mr. M. Hayashi of Kao Corporation for kindly supplying the fatty acids and derivatives used in the experiments.

This work was supported in a part by a Grant-in-Aid (Bio-Cosmos Program) from the Ministry of Agriculture, Forestry and Fisheries. (BCP 91-II-B-1)

\section{REFERENCES}

1) Czerkawski, J. W., Effect of linseed oil fatty acids and linseed oil on rumen fermentation in sheep. J. Agric. Sci., Camb., 81, 517-531 (1973).

2) Dawson, R. M. and Kemp, P., The effect of defaunation on the phospholipids and on the hydrogenation of unsaturated fatty acids in the rumen. Biochem. J., 115, 351-352 (1969).

3) Freese, E., Sheu, C. W., and Galliers, E., Function of lipophilic acids as antimicrobial food additives. Nature, 241, 321-325 (1973).

4) Galbraith, H., Miller, T. B., Paton, A. M., and Thompson, J. K., Antibacterial activity of long chain fatty acids and the reversal with calcium, magnesium, ergocalciferol and cholesterol. J. Appl. Bact., 34, 803-813 (1971).

5) Grummer, R. R. and Socha, M. T., Milk fatty acid composition and plasma energy metabolite concentrations in lactating cows fed medium-chain triglycerides. J. Dairy Sci., 72, 1996-2001 (1989).

6) Henderson, C., The effects of fatty acids on pure cultures of rumen bacteria. J. Agric. Sci., Camb., 81, 107-112 (1973).

7) Jouany, J. P. and Ushida, K., Protozoa and fibre digestion in the rumen. In The Rumen Ecosystem, ed. by Hoshino, S., Onodera, R., Minato, H., and Itabashi, H., Japan Scientific Societies Press/Springer Verlag, Tokyo (1990), p. 139-150.

8) Kato, N. and Shibasaki, I., Comparison of antimicrobial activities of fatty acids and their esters. J. Ferment. Technol., 53, 793-801 (1975).

9) Kobayashi, T., Matsumoto, M., and Itabashi, H., Effect of monensin on postprandial changes of rumen fermentation of steers fed grass silage and concentrate. Jpn. J. Zootech. Sci., 53, 528-534 (1982).

10) Lai, J.-S., Okuda, S., and Takahashi, H., Lipid A, various fatty acid, and their derivatives as proton conductors in membrane vesicles from Escherichia coli. J. Gen. Appl. Microbiol., 23, 137146 (1977).

11) Maczulak, A. E., Dehority, B. A., and Palmquist, D. L., Effects of long-chain fatty acids on growth of rumen bacteria. Appl. Environ. Microbiol., 42, 856-862 (1981).

12) Maxcy, R. B. and Dill, C. W., Adsorption of free fatty acids on cells of certain microorganisms. J. Dairy Sci., 50, 472-476 (1967).

13) Nakagawa, Y., Tawaratani, T., Kourai, H., Horie, T., and Shibasaki, I., Adsorption of Escherichia coli onto insolubilized lauryl pyridinium iodine and its bacteriostatic action. Appl. Environ. 
Microbiol., 47, 88-93 (1984).

14) Newbold, C. J. and Chamberlain, D. G., Lipids as rumen-defaunating agents. Proc. Nutr. Soc., 47, 154A (1988).

15) Nieman, C., Influence of trace amounts of fatty acids on the growth of microorganisms. Bacteriol. Rev., 18, 147-163 (1954).

16) Palmquist, D. L. and Jenkins, T. C., Fat in lactation rations: Review. J. Dairy Sci., 63, 1-14 (1980).

17) Sato, H., Tsuneishi, E., Hanasaka, S., and Watanabe, A., Effect of medium chain triglycerides on ruminal fermentation, feed digestion and blood properties in young calves. Anim. Sci. Technol. (Jpn.), 62, 142-147 (1991).

18) Schneider, P., Sklan, D., Chalupa, W., and Kronfeld, D. S., Feeding calcium salts of fatty acids to lactating cows. J. Dairy Sci., 71, 2143-2150 (1988).

19) Sutton, J. D., Knight, R., McAllan, A. B., and Smith, R. H., Digestion and synthesis in the rumen of sheep given diets supplemented with free and protected oils. Brit. J. Nutr., 49, 419-432 (1983).

20) Tsuchido, T., Hiraoka, T., Takano, M., and Shibasaki, I., Involvement of autolysin in cellular lysis of Bacillus subtilis induced by short- and medium-chain fatty acids. J. Bacteriol., 162, 42-46 (1985). 